\title{
Evaluation of specific antibody responses to selected malaria vaccine candidates in Zimbabwean children
}

\author{
A Marume ${ }^{1}$, G. Nyandoro ${ }^{* 2}$, I Mutingwende ${ }^{3}$, M. Tshabalala ${ }^{4}$, T. Gozho ${ }^{5}$, N Paul ${ }^{5}$, J. Gusha ${ }^{1}$, E Zumbika ${ }^{6}$, N. \\ Midzi $^{2}$, Takafira Mduluza ${ }^{5}$ \\ ${ }^{1}$ Department of Para-clinical Veterinary Sciences, University of Zimbabwe, Harare, Zimbabwe \\ ${ }^{2}$ Department of Medical Microbiology, College of Health, University of Zimbabwe, Harare, Zimbabwe \\ ${ }^{3}$ School of Pharmacy, University of Zimbabwe, Harare, Zimbabwe \\ ${ }^{4}$ Immunology Department, College of Health Sciences, University of Zimbabwe, Harare, Zimbabwe \\ ${ }^{5}$ Department of Biochemistry, University of Zimbabwe, Harare, Zimbabwe \\ ${ }^{6}$ Department of Applied Biology and Biochemistry, National University of Science and Technology, Harare, Zimbabwe
}

Received: July 13, 2015

DOI: $10.5430 / \mathrm{cns} . v 4 \mathrm{n} 1 \mathrm{p} 16$
Accepted: October 12, 2015

Online Published: November 16, 2015

\begin{abstract}
Introduction: There is high malaria related morbidity and mortality amongst infants and children in malaria endemic areas. An In-depth understanding of protective immunity correlates enables the long due necessary development of an effective malaria vaccine. This study aimed at evaluating antibody responses to apical membrane antigen 1 (AMA 1) that helps P falciparum entry into red blood cells, Glutamate rich protein (GLURP), an antigen expressed in the whole life cycle of the malaria causing pathogen, merozoite surface protein-1 (MSP 1) coding for a major antigen in the asexual stage of P falciparum and merozoite surface protein 3 (MSP 3), a polymorphic blood stage malaria antigen in Zimbabwean children living in malaria endemic areas. Methods: We characterized humoral immune responses to malaria vaccine candidates in a two year longitudinal survey among 136 children (6-16 years) from Burma and Kariba in Zimbabwe. Blood samples were collected and analyzed for malaria parasites, plasma and antibody titers against malaria vaccine candidates [MSP1, MSP3, GLURP, AMA] by ELISA technique. The blood samples were also checked for potential confounders like anemia, bilharzia and HIV sero-status using the ELISA technique.

Results: Ig levels were significantly different $(p<.0001)$ across the three time points, and against the different candidates $(p$ $<.0001)$. MSP3 had the highest $(13,552.2)$ and GLURP the least $(4,741.6) \operatorname{IgM}$ titers. However, $\operatorname{IgG}, \operatorname{IgG} 1, \operatorname{IgG} 3$ and $\operatorname{IgG} 4$ levels were highest against AMA compared to other vaccine candidates, [anti-MSP3 IgG3 (15.3) and anti-GLURP IgG4 (58.7)]. Anemia burden was about $44 \%$ at baseline with a threefold decrease (-16\%) over the 12 month follow up.

Conclusions: This study highlights the need for robust evaluation of several malaria vaccine candidates in combination to understand correlates of protective immunity as suggested by the significant antibody levels against the four vaccine candidates. Longer follow up periods are needed to assess the impact of continuous malaria exposure on host immune responses. Multivalent malaria vaccine development offer a better chance towards an efficacious malaria vaccine compared to monovalent vaccine. Antibody levels against the four vaccine candidates were significant suggesting that an ideal malaria vaccine should target more than one antigen.
\end{abstract}

Key Words: Malaria vaccine, Children, Antibody responses

*Correspondence: G. Nyandoro; Email: georgenyandoro@yahoo.com; Address: Department of Medical Microbiology, College of Health, University of Zimbabwe, Harare, Zimbabwe. 


\section{INTRODUCTION}

The World Health Organization estimated about 3.3 billion people being at risk of malaria by 2011 , with $80 \%$ of these people in sub Saharan Africa. ${ }^{[1]}$ There is however a marked decrease in burden in Southern Africa, mostly owing to intervention strategies: although with varying degrees of decrease in different countries within this region, some areas have had resurgence of malaria. ${ }^{[2-5]}$ Malaria is a major contributor to high morbidity and mortality in the Zimbabwean population $^{[6,7]}$ despite the massive campaign of control strategies. There is however a marked decrease in malaria related mortality rates globally (45\%), with most of the African countries recording a $49 \%$ decrease. Malaria related mortality rates in African children remains high (54\%). ${ }^{[8]}$ In Zimbabwe, 100\% of malaria infections are caused by Plasmodium falciparum (P. falciparum) ${ }^{[1]}$ with about 70 other species known to cause malaria in other parts of the world, and to other animal hosts other than humans.

It is important to note that the same populations with a burden of malaria have high numbers of other major infections like human immunodeficiency virus (HIV), helminthes and Mycobacterium tuberculosis (Mtb). Human co-infection with P. falciparum and helminthes is common trend in Africa, with school going age groups having the highest risk. ${ }^{[9]}$ Zimbabwean primary school children have a high risk of malaria and helminthes infections, a phenomenon that raises concern in incorporating helminthes control in the existing malaria control strategies. ${ }^{[10]}$

The development of a safe and effective malaria vaccine remains an urgent unmet medical need for vast populations living in malaria-endemic regions; and for those visiting these regions. Because severe morbidity and mortality due to P. falciparum disproportionately occurs in infants and young children living in sub-Saharan Africa; Zimbabwe included, this target population has been the principal focus of malaria vaccine development. Recently, significantly increased funding through private and public partnerships has encouraged the industrial sector to become more involved in the development of candidate malaria vaccines. ${ }^{[8]}$ This process in turn has led to more clearly articulated target product profiles and clinical development plans that have facilitated decision making and promoted rapid progress on several fronts. ${ }^{[1]}$

Among several human pathogens, malaria gives insights into the difficulty in designing an effective vaccine. ${ }^{[12]}$ Malaria vaccine strategies target the different life cycle stages of the causative pathogen: that is the sporozoites and liver stages, the blood stages and the gametocyte stages. In-depth understanding of protective immunity correlates is key in designing an effective malaria vaccine. Whole sporozoites vaccination strategy target the pre-erythrocytic stages of the malaria parasite. ${ }^{[13]}$ Attenuated whole parasite approaches to malaria vaccine design together with the subunit approaches have gave hope to an effective malaria. ${ }^{[14]}$ Although the mechanisms and specific targets are not well characterized, it is apparent that anti-merozoite antibodies are key in protective immunity against malaria. Most malaria antigens evoke a distinct IgG immune response, with different IgG sub classes being implicated. ${ }^{[15]}$ Measurement of humoral immune responses is the best standardized method of accessing protective immunity following vaccination. ${ }^{[16]}$ Immunoglobulin quantification by enzyme linked Immunosorbent assay (ELISA) correlate with protection against several infections including Plasmodium falciparum. ${ }^{[17]}$ There is slow development of immunity to malaria following infection, and immune responses only improve after the second exposure to the malaria pathogen. ELISA evaluation of immune responses. ${ }^{[18]}$

There is no available malaria vaccine as yet despite the extensive research and development efforts. Other socio-economic issues are of concern during the development of vaccines, including the acceptance or uptake of a new vaccine. ${ }^{[19,20]}$ Incorporating malaria vaccines during childhood vaccination campaigns would be ideal for most nations. ${ }^{[21]}$ Despite heavy efforts in developing a vaccine, there is currently no licensed malaria vaccine. ${ }^{[20]}$ Should a malaria vaccine become available in the future, a strategy to integrate it into the immunization programmes would be most ideal approach. ${ }^{[22]}$ Challenges for developing an effective malaria vaccine include weak regulatory frameworks of clinical trial administration especially in endemic areas. ${ }^{[23]}$ Efficacy evaluation of an effective malaria vaccine especially in phase II clinical trials are met with logistical challenges like unstandardised description of clinical and severe malaria definitions across malaria endemic nations to facilitate vaccine candidate evaluation. ${ }^{[16]}$ Our current study aimed at evaluating antibody responses to apical membrane antigen 1 (AMA 1) that helps P falciparum entry into red blood cells, Glutamate rich protein (GLURP), an antigen expressed in the whole life cycle of the malaria causing pathogen, merozoite surface protein-1 (MSP 1) coding for a major antigen in the asexual stage of P falciparum and merozoite surface protein 3 (MSP 3), a polymorphic blood stage malaria antigen in Zimbabwean children living in malaria endemic areas.

\section{MeTHODS}

\subsection{Study design and population}

Ethical approval was sought and granted by the Medical Research Council of Zimbabwe to conduct a longitudinal survey of humoral immune responses to malaria vaccine candidates among 136 children (aged between 6 and 16 years) 
from Burma and Kariba in Zimbabwe. The Burma Valley in Eastern Zimbabwe and Kariba are malaria endemic areas. ${ }^{[24-26]}$ Written informed consent was sought from all the participants together with assent from their parents/guardians to partake in the study. Each study participants' demographic data was collected and recorded during the two year follow up period.

\subsection{Sample collection and diagnosis}

Whole blood samples were collected at baseline, six month and twelve month follow up period in accordance with the WHO guidelines in EDTA containing tubes. ${ }^{[1]}$ The collected blood samples were processed to collect plasma and serum which were stored at $-80^{\circ} \mathrm{C}$ until processed. Thick and thin smears (gold standard for confirming malaria) were done for peripheral malaria parasite (MP) examination. The blood samples were also checked for anemia, bilharzia and HIV sero-status.

2.3 Humoral Immune response measurement by ELISA Humoral immune responses against vaccine candidates (malaria antigens) AMA1, GLURP, MSP1 and MSP3 were assessed by ELISA technique. Immunoglobulin (Ig) levels [IgM, IgG, IgG1, IgG3 and IgG4] against the four malaria vaccine candidates AMA1, GLURP, MSP1 and MSP3 were determined by ELISA. The quantification was done using Afro Immuno-Assay standard procedure according to the manufacturer's instructions as previously described. ${ }^{[1,13,17,27-30]}$ Briefly; 96 well Nunc MaxiSorbTM microtitre plates (Nunc, Denmark) were coated overnight at $4^{\circ} \mathrm{C}$ with $100 \mu \mathrm{l} /$ well of recombinant $\mathrm{P}$. falciparum antigen (1.0 $\mu \mathrm{g} / \mathrm{ml}$ for AMA-1, MSP1 and MSP-3 and $0.5 \mu \mathrm{g} / \mathrm{ml}$ for GLURP) in columns 3-12 and with serial dilutions of standard reference in columns 1 and 2 . The unbound antigens were removed by washing with PBS/0.1\% Tween 20 washing buffer. After washing, $150 \mu \mathrm{l} /$ well of $3 \%$ skimmed milk powder in PBST (free antigen blocking buffer) was added into each well, followed by plate washing as before. After the second wash, $100 \mu \mathrm{l} /$ well of diluted plasma was added to columns 5-12 of each plate in duplicate, columns 3 and 4 were for positive and negative controls respectively. The plates were then incubated at room temperature for two hours before washing as before. Peroxidase conjugated goat anti-human $\mathrm{IgM} / \mathrm{IgG}$ (Caltag) for IgM and $\mathrm{IgG}$ quantification and mouse anti-human IgG1/IgG3/IgG4 for IgG1, IgG3 and IgG4 quantification (100 $\mu \mathrm{l} /$ well) were added, and then they were left in plates for an hour. The detection stage involved adding $100 \mu \mathrm{l} /$ well of HRP substrate and a 30 minutes incubation in the dark. The reaction was then stopped by the addition of $100 \mu \mathrm{l} /$ well of $0.2 \mathrm{M}$ sulphuric acid $\left(\mathrm{H}_{2} \mathrm{SO}_{4}\right)$ and absorbance was read at $492 \mathrm{~nm}$ with a multiscan ELISA plate reader. The recorded OD values were inferred to antibody concentrations by using a standard curve derived from the standards in the assay.

\subsection{Statistical analysis}

The data was analysed using SAS (SAS, 2010) software. Stratified analysis and Multivariate Analysis of Variance (MANOVA) methods were used to control for confounders and to detect mean difference due to effects of antibody immune responses; and the means were separated by adjusted Tukey methods.

\section{RESULTS}

\subsection{Demographic information}

Serum samples used in the study were obtained from 136 children residing in malaria endemic Burma and Kariba areas in Zimbabwe. The mean age of the participants was 9.8 years (standard deviation, SD 2.2). Only one (0.7\%) participant was HIV seropositive with the rest being negative. Table 1 summarizes the demographic characteristics of the study population.

Table 1. Demographic characteristics of the study population

\begin{tabular}{ll}
\hline Characteristics & Frequency $\boldsymbol{n}(\%)$ \\
\hline Age mean (SD) years & $9.8(2.2)$ \\
Gender & \\
$\quad$ Male & $58(42.6)$ \\
$\quad$ Female & $78(57.4)$ \\
HIV status & \\
$\quad$ Sero positive & $1(0.7)$ \\
$\quad$ Sero negative & $135(99.3)$ \\
Schistosoma infection status & \\
$\quad$ Positive & $116(85.3)$ \\
$\quad$ Negative & $20(14.7)$ \\
\hline
\end{tabular}

Note. SD = Standard deviation; The study group comprised mainly girls $(\sim 58 \%)$, with most of the participants (85.3\%) being infected by schistosomiasis

\subsection{Anemia amongst the study participants}

Anemia was defined as hemoglobin less than $13 \mathrm{mg} / \mathrm{dl}$ in men or less than $12 \mathrm{mg} / \mathrm{dl}$ in women as previously described. ${ }^{[31]}$ At baseline, $44.1 \%$ of children enrolled in the study were anemic, with the burden decreasing over the 12 month follow up period. As shown in detail in Figure 1, the percentage of anemic children decreased from $44.1 \%$ at baseline to $20.4 \%$ and $15.8 \%$ in 6 month and 12 month follow up periods respectively. 


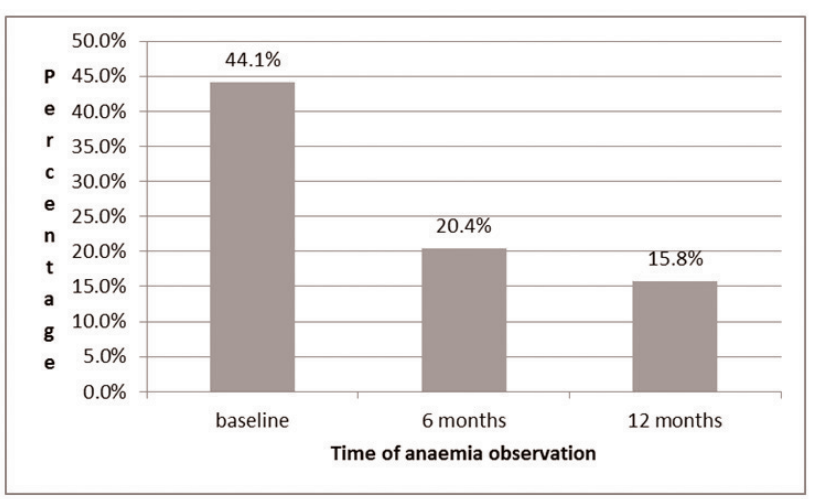

Figure 1. Anemia status of study participants at baseline, after six months and after twelve months

\subsection{Immunoglobulin levels elicited by different vaccine candidates}

We analyzed antibody levels [IgM, IgG, IgG1, IgG3 and IgG4] stratified by age, gender, follow up period, malaria infection status and the different vaccine candidates as summarized in Table 2.

IgM levels were statistically different between males and females $(p=.002)$, with other Ig being insignificantly different between the genders. The age of participants significantly influenced IgM levels ( $p=.049$ ), but was insignificant for IgG, $\mathrm{IgG1}$, IgG3 and IgG4 levels. Antibody levels were not significantly different between the malaria positive and malaria negative samples of the study population. The five Ig levels measured at baseline, six months and twelve month were significantly different $(p<.0001)$ across the three time points, suggesting that duration of exposure to malaria significantly influence humoral immune responses of individuals. All Ig levels against the four malaria vaccine candidates were statistically significant $(p<.0001)$ as shown in Table 2 . MSP3 vaccine candidate had the highest IgM levels $(13,552.2)$ and GLURP $(4,741.6)$ with the least IgM antibody titers. However, IgG, IgG1, IgG3 and IgG4 levels were highest against AMA compared to other vaccine candidates, with very low IgG3 levels (15.3) against MSP3 and IgG4 (58.7) against GLURP (see Table 2).

\section{Discussion}

Malaria is still a global problem despite efforts to eradicate the tropical disease. ${ }^{[6,7,32]}$ Malaria vaccine development efforts target different stages of the parasite life cycle, and there is growing evidence that no single antigen based vaccine is effective in controlling malaria. ${ }^{[32]}$ We sought to evaluate humoral immune responses against AMA, MSP1, MSP3 and GLURP malaria vaccine candidates amongst children in a malaria endemic area in Zimbabwe. Although children are at higher risk of malaria acquisition and developing severe malaria disease, they tend to develop protective immunity faster than adults. They are an ideal population to test the efficacy of the different vaccine candidates. ${ }^{[33]}$

In our current study; anemia burden was about $44 \%$ at baseline with a threefold decrease (approximately 16\%) over the 12 month follow up period. Global anemia problem is most pronounced in South Asia and sub-Sahara regions with females more burdened than males. The major causes of anemia are iron deficiency and infections like malaria and schistosomiasis. Children under five years are the highly anemia affected age groups. ${ }^{[34]}$ Anemia contributes more than $50 \%$ of malaria related deaths globally. ${ }^{[35,36]}$ Malaria causes anemia through destruction of red blood cells (hemolysis), increased clearance of infected and uninfected red blood cells by the spleen, and cytokine-induced dyserythropoiesis (abnormal formation of red blood cells). Anemia has thus implications on the design and development of malaria vaccines.

We also evaluated the contribution of schistosomiasis on anemia. There was a decrease in anemia burden amongst Schistosoma negative children compared to Schistosoma positive children overtime. Schistosoma and malaria treatment might have contributed to the overall decrease in anemia incidence. The study findings are in agreement with Soares $e t$ al. 2013, which showed a decrease of anemia burden through treatment of Schistosoma haematobium infections. ${ }^{[37]}$ This notion supports the need for concerted efforts in controlling helminthes infections to reduce the global childhood anemia burden. Other studies have confirmed a reduction in childhood anemia through malaria control in malaria endemic areas in Africa. ${ }^{[38]}$

Although only one participant was HIV positive in our current study, HIV and malaria co infections have claimed several lives globally especially in developing nations. ${ }^{[39,40]}$ HIV infection is associated with an increased risk of clinical malaria. ${ }^{[41,42]}$ Other studies though have showed no major differences in malaria clinical outcomes between HIV positive and negative populations. ${ }^{[43-45]}$

Many epidemiological, clinical and laboratory data has shown that women generally have higher serum immunoglobulin levels and mount stronger antibody responses following vaccination or infection compared to their male counterparts. ${ }^{[46]}$ Our current study demonstrated then significant antibody levels between male and female participants. The gender difference in antibody levels may be explained by differences in gonadal steroid hormones blood. Female hormone, estrogen, stimulates immune responses whilst male hormone, testosterone is immunosuppressive. ${ }^{[47,48]}$ It is thus important to evaluate humoral immune responses to malaria 
vaccine candidates amongst male and female children. This study demonstrated the potential of AMA1, MSP1, MSP3 and GLURP as potential malaria vaccine candidates since all the antigens elicited a humoral immune response which was measured by ELISA. The varying antibody levels against the studied antigens suggest differing immunogenicity of these vaccine candidates.

Table 2. Summary of Immunoglobulin levels stratified by different parameters

\begin{tabular}{|c|c|c|c|c|c|}
\hline \multirow{2}{*}{ Parameter } & \multicolumn{5}{|c|}{ Mean Immunoglobulin levels } \\
\hline & IgM & IgG & IgG1 & IgG3 & IgG4 \\
\hline \multicolumn{6}{|l|}{ Gender } \\
\hline Males $(n=58)$ & $9,571.8$ & $374,539.0$ & $39,055.0$ & $8,727.7$ & $13,239.0$ \\
\hline Females $(n=78)$ & $11,497.8$ & $454,131.0$ & $44,025.0$ & $9,465.6$ & $11,312.0$ \\
\hline$p$ value & $.002^{*}$ & $.1135^{\#}$ & $.508^{\#}$ & $.414^{* \#}$ & $.182^{\#}$ \\
\hline \multicolumn{6}{|l|}{ Age (yrs) } \\
\hline$<10(n=57)$ & $9,916.2$ & $455,055.0$ & $44,851.0$ & $9,762.8$ & $10,851.0$ \\
\hline$\geq 10(n=79)$ & $10,868.1$ & $380,721.0$ & $38,892.0$ & $8,578.6$ & $13,402.0$ \\
\hline$p$ value & $.142^{\#}$ & $.112^{\#}$ & $.383^{\#}$ & $.134^{\#}$ & $.049^{*}$ \\
\hline \multicolumn{6}{|l|}{ Period (months) } \\
\hline $0(n=49)$ & $10,327.7$ & $900,014.0$ & $39,916.0$ & $7,908.5$ & $16,396.0$ \\
\hline $6(n=45)$ & $18,194.3$ & $223,452.0$ & $68,607.0$ & $14,291.3$ & $13,649.0$ \\
\hline $12(n=42)$ & $2,389.0$ & $54,076.0$ & $13,969.0$ & $4,831.0$ & $6,298.0$ \\
\hline$p$ value & $<.0001^{*}$ & $<.0001^{*}$ & $<.0001^{*}$ & $<.0001^{*}$ & $<.0001^{*}$ \\
\hline \multicolumn{6}{|l|}{ Malaria status } \\
\hline Positive $(n=44)$ & $10,784.0$ & $568,422.0$ & $40,746.0$ & $8,696.7$ & $13,272.0$ \\
\hline Negative $(n=92)$ & $10,322.8$ & $337,317.0$ & $41,675.0$ & $9,250.6$ & $11,896.0$ \\
\hline$p$ value & $.941^{\#}$ & $.976^{\#}$ & $.676^{\#}$ & $.536^{\#}$ & $.835^{\#}$ \\
\hline \multicolumn{6}{|l|}{ Vaccine candidate } \\
\hline $\operatorname{AMA}(n=35)$ & $6,091.3$ & $814,496.4$ & $48,166.6$ & $9,004.7$ & $16,860.1$ \\
\hline $\operatorname{MSP} 1(n=35)$ & $6,311.7$ & $171,624.2$ & $4,439.8$ & $3,641.9$ & $5,700.1$ \\
\hline $\operatorname{MSP} 3(n=33)$ & $13,552.2$ & $84,859.9$ & $5,925.0$ & 15.9 & $2,395.2$ \\
\hline GLURP $(n=33)$ & $4,741.6$ & $49,798.1$ & $5,515.7$ & $3,370.6$ & 58.7 \\
\hline$p$ value & $<.0001^{*}$ & $<.0001^{*}$ & $<.0001^{*}$ & $<.0001^{*}$ & $<.0001^{*}$ \\
\hline
\end{tabular}

Note. ${ }^{*}$ statistically different at alpha $=0.05 ;{ }^{*}$ not statistically different at alpha $=0.05$

Protective humoral immunity to malaria is achieved after several years of re-infections; hence malaria is a major concern in endemic areas. Natural immunity to malaria is associated with prolonged exposure to the parasite. The ratio of naïve memory $\mathrm{T}$ cells decrease with age together with the ability of the thymus to produce more naïve T cells. ${ }^{[49]}$ Our study results show a significant difference in antibody levels measured at baseline, six and twelve month follow up period, thereby supporting the theory that protective immunity to malaria develops over time and through re infections. Although our results did not show an association between parasitemia levels and antibody levels, we expected high antibody titers in participants with high malaria parasite counts. Although in our current study, age influenced IgM levels sig- nificantly, Dodoo et al. 2008, showed an increase in IgG with age. ${ }^{[50]}$ Ladeia-Andrade et al. 2009, suggested an increasing malaria infection rate with increasing age, and induction of a significant anti parasite immunity amongst native Amazonians in Brazil. ${ }^{[51]}$ Some studies have shown a negative correlation between IgM levels parasitemia levels. ${ }^{[52]}$ IgM is a potent inducer of the complement system which might contribute to anti-malaria immunity. ${ }^{[52,53]}$ Specific antibodies might promote antibody dependant phagocytosis, with IgM being more protective than $\operatorname{IgG} .^{[52,54]}$ Our study found high anti MSP3 IgM and very low levels of anti GLURP IgM. Brown et al. 1986, suggest that IgM plays a critical role in malaria resistance compared to $\operatorname{IgG}^{\left[{ }^{[5]}\right.}$ In other studies, anti MSP1 IgM and IgG antibodies were associated with 
protective role to malaria in infants and pregnant women. ${ }^{[55]}$

Total IgG levels were high across all the tested vaccine candidates as compared to $\mathrm{IgG}$ subclasses (IgG1, IgG3 and $\mathrm{IgG} 4$ ). In a related study, IgG1, IgG2 and IgG3 were significantly high in complicated malaria cases compared to no complicated malaria. IgG3 was shown to be associated with a reduced risk of complicated malaria in this study. ${ }^{[56]}$ Another study showed profound differences in the distribution of immunoglobulin subclasses between clinically protected and susceptible individuals, with cytophilic subclasses (IgG1 and IgG3) being dominant in protected individuals while non-cytophilic antibodies were predominant in non-protected individuals. ${ }^{[57]}$

GLURP from Plasmodium falciparum is present in all stages of the parasite in humans, and is highly conserved in geographically distant P. falciparum isolates. Anti GLURP antibodies target the erythrocyte and hepatic stages of malaria, and stimulate both B and T cell immune responses. ${ }^{[58]}$ This class of antibodies was shown to be high in clinically ill children compared to the asymptomatic one, suggesting the importance of anti GLURP antibodies in malaria immunity. ${ }^{[59]}$ MSP3 and GLURP proteins have been shown to have a complementary effect that provides a rationale for combining these two antigens in a hybrid vaccine formulation. ${ }^{[60]}$ MSP119 and apical membrane antigen 1 (AMA1) antibodies have also been shown to be associated with a reduced risk of clinical malaria. ${ }^{[55]}$ Multivalent malaria vaccine development offer a better chance towards an efficacious malaria vaccine compared to monovalent vaccine. ${ }^{[50]}$ Antibody levels against the four vaccine candidates were significant suggesting that an ideal malaria vaccine should target more than one antigen.

Despite being a global problem, there is currently no licensed malaria vaccine. Our study sought to evaluate malaria vaccine candidates in children living in malaria endemic area.
All the vaccine candidates were shown to be potentials in an effective malaria vaccine, although our study did not assess cell mediated immune responses elicited by the vaccine candidates. The high anemia incidence in our study warrants the need for routing screening, treatment and prevention of both malaria and schistosomiasis. We conclude that there is need for robust evaluation of several vaccine candidates in combination to come with a protective malaria vaccine that will evoke both humoral and cell mediated immune responses. Longer follow up periods are needed to assess the impact of continuous malaria exposure on host immune responses.

\section{Conclusions}

We conclude that there is need for robust evaluation of several vaccine candidates in combination to come with a protective malaria vaccine that will evoke both humoral and cell mediated immune responses. Longer follow up periods are needed to assess the impact of continuous malaria exposure on host immune responses. Multivalent malaria vaccine development offer a better chance towards an efficacious malaria vaccine compared to monovalent vaccine. Antibody levels against the four vaccine candidates were significant suggesting that an ideal malaria vaccine should target more than one antigen.

\section{ACKNOWLEDGeMENTS}

Part of this study was submitted to the Department of Applied Biology and Biochemistry, Faculty of Applied Sciences, National University of Science and Technology (NUST) Gwanda Road/Cecil Ave, POBox AC 939, Ascot, Bulawayo, Zimbabwe as Partial fulfillment of an MSc in Applied Microbiology and Biotechnology degree programme, June 2012 by Amos Marume.

\section{CONFlicts OF INTEREST Disclosure}

The authors declare that there is no conflict of interests regarding the publication of this paper.

\section{REFERENCES}

[1] WHO: World malaria report: 2012. In. Edited by 2012 WHO. Geneva; 2012.

[2] Moonasar D, Nuthulaganti T, Kruger P, et al. Malaria control in South Africa 2000-2010: beyond MDG6. Malaria Journal. 2012; 11(1): 294. PMID:22913727. http://dx.doi.org/10.1186/1475-2875-1 $1-294$

[3] O'Meara WP, Bejon P, Mwangi TW, et al. Effect of a fall in malaria transmission on morbidity and mortality in Kilifi, Kenya. Lancet. 2008; 372(9649): 1555-1562. http://dx.doi.org/10.1016/S 0140-6736 (08) 61655-4

[4] O'Meara WP, Mangeni JN, Steketee R, et al. Changes in the burden of malaria in sub-Saharan Africa. Lancet Infect Dis. 2010; 10(8): 545555. http://dx.doi .org/10.1016/S1473-3099(10)70096-7

Published by Sciedu Press
[5] Mharakurwa S, Thuma PE, Norris DE, et al. Malaria epidemiology and control in Southern Africa. Acta Trop. 2012; 121(3): 202-206. PMID:21756864. http://dx.doi.org/10.1016/j.actatropi ca. 2011.06 .012

[6] Mharakurwa S, Mugochi T. Response of chloroquine-resistant falciparum malaria to sulfadoxine/pyrimethamine in Gokwe area of Zimbabwe. Cent Afr JMed. 1994; 40: 53-56. PMID:7923343.

[7] Mlambo G, Sullivan D, Mutambu SL, et al. High prevalence of molecular markers for resistance to chloroquine and pyrimethamine in Plasmodium falciparum from Zimbabwe. Parasitol Res. 2007; 101: 1147-1151. PMID:17546463. http://dx.doi.org/10.1007 /s00436-007-0597-5

[8] WHO: World malaria Report: 2013. In. Geneva; 2013.

[9] Brooker S, Akhwale W, Pullan R, et al. Epidemiology of Plasmodium- 
Helminth Co-Infection in Africa: Populations at Risk, Potential Impact on Anemia, and Prospects for Combining Control. The American Journal of Tropical Medicine and Hygiene. 2007; 77(6 Suppl): 88-98. PMID: 18165479.

[10] Midzi N, Sangweme D, Zinyowera S, et al. The burden of polyparasitism among primary schoolchildren in rural and farming areas in Zimbabwe. Trans R Soc Trop Med Hyg. 2008; 102(10): 1039-1045. PMID:18656215. http://dx.doi.org/10.1016/j.trstmh. 20 08.05 .024

[11] Ripley WB. Update on the clinical development of candidate malaria vaccines. Am J Trop Med Hyg. 2004; 71(Suppl 2): 239-247.

[12] Hill AVS. Vaccines against malaria. Phil Trans R Soc B. 2011; 366: 2806-2814. PMID:21893544. http://dx.doi.org/10.10 98/rstb.2011.0091

[13] Butler NS, Vaughan AM, Harty JT, et al. Whole parasite vaccination approaches for prevention of malaria infection. Trends Immunol. 2012; 33(5): 247-254. PMID:22405559. http://dx.doi .org/10. $1016 / j$.it.2012.02.001

[14] Vaughan AM, Kappe SH. Malaria vaccine development: persistent challenges. Curr Opin Immunol. 2012; 24(3): 324-331. PMID:22521906. http://dx.doi.org/10.1016/j.coi. 2012 . 03.009

[15] Stanisic DI, Richards JS, McCallum FJ, et al. Immunoglobulin G subclass-specific responses against Plasmodium falciparum merozoite antigens are associated with control of parasitemia and protection from symptomatic illness. Infect Immun. 2009; 77(3): 11651174. PMID:19139189. http://dx.doi.org/10.1128/IAI.011 29-08

[16] Moorthy V, Reed Z, Smith PG. Measurement of malaria vaccine efficacy in phase III trials: report of a WHO consultation. Vaccine. 2007 Jul 9; 25(28): 5115-23. PMID:17577487. http://dx.doi.o $\mathrm{rg} / 10.1016 / \mathrm{j}$. vaccine .2007 .01 .085

[17] Thakur A, Pedersen LE, Jungersen G. Immune markers and correlates of protection for vaccine induced immune responses. Vaccine. 2012; 30: 4907-4920. PMID:22658928. http://dx.doi .org/10. $1016 / j$. vaccine .2012 .05 .049

[18] Chuangchaiya S, Persson KE. How Should Antibodies against P. falciparum Merozoite Antigens Be Measured? J Trop Med. 2013; 493834(10): 18. http://dx.doi.org/10.1155/2013/493834

[19] Ballou WR, Arevalo-Herrera M, Carucci D, et al. Update on the clinical development of candidate malaria vaccines. Am J Trop Med Hyg. 2004; 71(2 Suppl): 239-247. PMID: 15331843.

[20] Mwangoka G, Ogutu B, Msambichaka B, et al. Experience and challenges from clinical trials with malaria vaccines in Africa. Malar J. 2013; 12(86): 1475-2875. http://dx.doi .org/10.1186/147 5-2875-12-86

[21] Bingham A, Gaspar F, Lancaster K, et al. Community perceptions of malaria and vaccines in two districts of Mozambique. Malar J. 2012; 11(394): 1475-2875. http://dx.doi.org/10.1186/147 5-2875-11-394

[22] Ojakaa D, Yamo E, Collymore Y, et al. Perceptions of malaria and vaccines in Kenya. Hum Vaccin. 2011; 7(10): 1096-1099. PMID:21941095. http://dx.doi.org/10.4161/hv.7.10.174 96

[23] Koram KA, Gyan BA. Malaria vaccine development: an endemic country perspective. Hum Vaccin. 2010; 6(1): 12-16. PMID:19806020. http://dx.doi.org/10.4161/hv.6.1.9605

[24] Mutapi F, Ndhlovu PD, Hagan P, et al. Anti-schistosome antibody responses in children coinfected with malaria. Parasite Immunol. 2000; 22(4): 207-209. PMID:10760187. http://dx.doi .org/10.1046 /j.1365-3024.2000.00288.x
[25] Macdonald F, Goldsmid JM. Intestinal helminth infections in the Burma Valley area of Rhodesia. Cent Afr J Med. 1973; 19(6): 113115. PMID:4737861.

[26] Taylor P, Mutambu SL. A review of the malaria situation in Zimbabwe with special reference to the period 1972-1981. Trans R Soc Trop Med Hyg. 1986; 80(1): 12-19. http://dx.doi.org/10.10 16/0035-9203(86) 90185-9.

[27] Riley EM, Stewart VA. Immune mechanisms in malaria: new insights in vaccine development. Nat Med. 2013; 19(2): 168-178. PMID:23389617. http://dx.doi.org/10.1038/nm. 3083

[28] Douradinha B, Doolan DL. Harnessing immune responses against Plasmodium for rational vaccine design. Trends Parasitol. 2011; 27(6): 274-283. PMID:21531627. http://dx.doi .org/10.1016 $/ j \cdot \mathrm{pt} .2011 .01 .002$

[29] Hoffman SL, Goh LM, Luke TC, et al. Protection of humans against malaria by immunization with radiation attenuated Plasmodium falciparum sporozoites. J Infect Dis. 2002; 185: 1155-1164. PMID:11930326. http://dx.doi.org/10.1086/339409

[30] Reddy SB, Anders RF, Beeson JG, et al. High affinity antibodies to Plasmodium falciparum merozoite antigens are associated with protection from malaria. PloS ONE. 2012; 7(2): 21. PMID:22363818. http://dx.doi.org/10.1371/journal . pone.0032242

[31] Ennezat PV, Marechaux S, Pincon C, et al. Anaemia to predict outcome in patients with acute coronary syndromes. Arch Cardiovasc Dis. 2013; 106(6-7): 357-365. PMID:23806304. http: //dx.doi.org/10.1016/j.acvd.2013.04.004

[32] Von Seidlein L, Bejon P. Malaria vaccines: past, present and future. Arch Dis Child. 2013; 98(12): 981-985. PMID:24061779. http://dx.doi.org/10.1136/archdischild-2013-304173

[33] Aponte JJ, Menendez C, Schellenberg D, et al. Age interactions in the development of naturally acquired immunity to Plasmodium falciparum and its clinical presentation. PLoS Med. 2007; 4(7): e242. PMID:17676985. http://dx.doi.org/10.1371/journal.pme d. 0040242

[34] Kassebaum NJ, Jasrasaria R, Naghavi M, et al. A systematic analysis of global anemia burden from 1990 to 2010. Blood. 2013; 2: 2.

[35] Newton CR, Warn PA, Winstanley PA, et al. Severe anaemia in children living in a malaria endemic area of Kenya. Trop Med Int Health. 1997; 2(2): 165-178. PMID:9472302. http://dx.doi.o $\mathrm{rg} / 10.1046 / \mathrm{j} .1365-3156.1997 . \mathrm{d} 01-238 \cdot \mathrm{x}$

[36] Quintero JP, Siqueira AM, Tobon A, et al. Malaria-related anaemia: a Latin American perspective. Mem Inst Oswaldo Cruz. 2011; 1: 91104. http://dx.doi.org/10.1590/S0074-027620110009000 12

[37] Soares Magalhaes RJ, Langa A, Pedro JM, et al. Role of malnutrition and parasite infections in the spatial variation in children's anaemia risk in northern Angola. Geospat Health. 2013; 7(2): 341-354. PMID:23733295. http://dx.doi.org/10.4081/gh.2013.91

[38] Korenromp EL, Armstrong-Schellenberg JR, Williams BG, et al. Impact of malaria control on childhood anaemia in Africa - a quantitative review. Trop Med Int Health. 2004; 9(10): 1050-1065. PMID:15482397. http://dx.doi.org/10.1111/j.1365-3156. 2004.01317.x

[39] Foca E, Odolini S, Brianese N, et al. Malaria and hiv in adults: When the parasite runs into the virus. Mediterr J Hematol Infect Dis. 2012; 4(1): 7. PMID:22708047. http://dx.doi.org/10.4084/mjhid .2012 .032$.

[40] Lozano R, Naghavi M, Foreman K, et al. Global and regional mortality from 235 causes of death for 20 age groups in 1990 and 2010: A systematic analysis for the Global Burden of Disease Study 2010. Lancet. 2012; 380(9859): 2095-2128. http://dx.doi.org/10. $1016 / \mathrm{S} 0140-6736$ (12) 61728-0 
[41] Kalyesubula I, Musoke-Mudido P, Marum L, et al. Effects of malaria infection in human immunodeficiency virus type 1-infected Ugandan children. Pediatr Infect Dis J. 1997; 16(9): 876-881. PMID:9306483. http://dx.doi.org/10.1097/00006454-199709000-00011

[42] Whitworth J, Morgan D, Quigley M, et al. Effect of HIV-1 and increasing immunosuppression on malaria parasitaemia and clinical episodes in adults in rural Uganda: a cohort study. Lancet. 2000; 356(9235): 1051-1056. http://dx.doi.org/10.1016/S0140-6 $736(00) 02727-6$

[43] Greenberg AE, Nsa W, Ryder RW, et al. Plasmodium Falciparum malaria and perinatally acquired human immunodeficiency virus type 1 infection in Kinshasa, Zaire. A prospective, longitudinal cohort study of 587 children. N Engl J Med. 1991; 325(2): 105109. PMID:2052043. http://dx.doi .org/10.1056/NEJM19910 7113250206

[44] Kashamuka M, Nzila N, Mussey L, et al. Short report: Analysis of anti-malaria immune response during human immunodeficiency virus infection in adults in Kinshasa, Democratic Republic of the Congo. Am J Trop Med Hyg. 2003; 68(3): 376-378. PMID:12685648.

[45] Nguyen-Dinh P, Greenberg AE, Mann JM, et al. Absence of association between Plasmodium falciparum malaria and human immunodeficiency virus infection in children in Kinshasa, Zaire. Bull World Health Organ. 1987; 65(5): 607-613. PMID:3322600.

[46] Schuurs AH, Verheul HA. Effects of gender and sex steroids on the immune response. J Steroid Biochem. 1990; 35(2): 157-172. http://dx.doi.org/10.1016/0022-4731 (90) 90270-3

[47] Kovacs EJ, Messingham KA. Influence of alcohol and gender on immune response. Alcohol Res Health. 2002; 26(4): 257-263. PMID: 12875035.

[48] Verthelyi D, Klinman DM. Sex hormone levels correlate with the activity of cytokine-secreting cells in vivo. Immunology. 2000; 100(3): 384-390. PMID:10929062. http://dx.doi.org/10.1046/j.1 $365-2567.2000 .00047 . x$

[49] Illingworth J, Butler NS, Roetynck S, et al. Chronic exposure to Plasmodium falciparum is associated with phenotypic evidence of B and T cell exhaustion. J Immunol. 2013; 190(3): 1038-1047. PMID:23264654. http://dx.doi.org/10.4049/jimmunol. 12 02438

[50] Dodoo D, Aikins A, Kusi KA, et al. Cohort study of the association of antibody levels to AMA1, MSP119, MSP3 and GLURP with protection from clinical malaria in Ghanaian children. Malar J. 2008; 7(142): 1475-2875. http://dx.doi .org/10.1186/147 5-2875-7-142
[51] Ladeia-Andrade S, Ferreira MU, de Carvalho ME, et al. Agedependent acquisition of protective immunity to malaria in riverine populations of the Amazon Basin of Brazil. Am J Trop Med Hyg. 2009; 80(3): 452-459. PMID:19270298.

[52] Boudin C, Chumpitazi B, Dziegiel M, et al. Possible role of specific immunoglobulin $\mathrm{M}$ antibodies to Plasmodium falciparum antigens in immunoprotection of humans living in a hyperendemic area, Burkina Faso. J Clin Microbiol. 1993; 31(3): 636-641. PMID:8458956.

[53] Phanuphak P, Hanvanich M, Sakulramrung R, et al. Complement changes in falciparum malaria infection. Clin Exp Immunol. 1985; 59(3): 571-576. PMID:3886219.

[54] Brown J, Greenwood BM, Terry RJ. Cellular mechanisms involved in recovery from acute malaria in Gambian children. Parasite Immunol. 1986; 8(6): 551-564. PMID:3543809. http://dx.doi.org /10.1111/j.1365-3024.1986.tb00869.x

[55] Branch OH, Udhayakumar V, Hightower AW, et al. A longitudinal investigation of $\mathrm{IgG}$ and $\mathrm{IgM}$ antibody responses to the merozoite surface protein-1 19-kiloDalton domain of Plasmodium falciparum in pregnant women and infants: Associations with febrile illness, parasitemia, and anemia. Am J Trop Med Hyg. 1998; 58(2): 211-219. PMID:9502606.

[56] Tangteerawatana P, Montgomery SM, Perlmann H, et al. Differential regulation of $\operatorname{IgG}$ subclasses and $\operatorname{IgE}$ antimalarial antibody responses in complicated and uncomplicated Plasmodium falciparum malaria. Parasite Immunol. 2007; 29(9): 475-483. PMID:17727571. http://dx.doi.org/10.1111/j.1365-3024.2007.00965.x

[57] Bouharoun-Tayoun H, Druilhe P. Antibodies in falciparum malaria: What matters most, quantity or quality? Mem Inst Oswaldo Cruz. 1992; 3: 229-234. http://dx.doi.org/10.1590/S0074-02761 992000700038

[58] Borre MB, Dziegiel M, Hogh B, et al. Primary structure and localization of a conserved immunogenic Plasmodium falciparum glutamate rich protein (GLURP) expressed in both the preerythrocytic and erythrocytic stages of the vertebrate life cycle. Mol Biochem Parasitol. 1991; 49(1): 119-131. http://dx.doi .org/10.1016/0166-685 1 (91) $90135-\mathrm{S}$

[59] Dziegiel M, Rowe P, Bennett S, et al. Immunoglobulin M and G antibody responses to Plasmodium falciparum glutamate-rich protein: Correlation with clinical immunity in Gambian children. Infect Immun. 1993; 61(1): 103-108. PMID:8418032.

[60] Oeuvray C, Bouharoun-Tayoun H, Gras-Masse H, et al. Merozoite surface protein-3: A malaria protein inducing antibodies that promote Plasmodium falciparum killing by cooperation with blood monocytes. Blood. 1994; 84(5): 1594-1602. PMID:8068948. 